\title{
Artefact Kinds Need Not Be Kinds of Artefacts
}

\author{
Ludger Jansen
}

\begin{abstract}
This paper questions the widespread supposition that artefact kinds are kinds of artefacts. I will argue that this supposition rests on a one-sided diet of examples taken from inanimate physical things and the neglect of social and biological artefacts. I will argue that belonging to an artefact kind and being an artefact are independent features: The first divides off artefacts from non-artefacts, the second rests on the distinction between instances of artefact kinds and instances of natural kinds. I claim that these two distinctions are orthogonal to each other, and besides the two canonical combinations of artificial instances of artefact kinds and nonartificial instances of natural kinds there are also non-artificial instances of artefact kinds and artificial instances of natural kinds. Moreover, as some artificial living beings are self-reproducing, some instances of an artefact kind are not themselves artefacts. Hence artefact kinds are not of necessity kinds of artefacts.
\end{abstract}

\section{Introduction}

Artefacts are typically imagined as inanimate physical things. Paradigmatic examples for such a conception of artefacts are screw drivers, frying pans, and nuclear power plants. Every single screw driver belongs to the artefact kind of screw drivers, and, or so the story goes, every instance of that kind is an artefact and has an artificial origin. In what follows, I challenge this view: Artefacts can also be living beings and even non-material entities. Taking this broader perspective, I will argue that artefacts need not belong to artefact kinds; they can as well belong to natural kinds.

For arguing thus, we first need a working definition of what it is to be an artefact, and I will define artefacts as useful objects that have been intentionally made for this use (Section 2). The discussion of money, a paradigmatic social artefact, will show that artefacts are not correctly described as mere re-arrangement of pre-existing parts (Section 3). While typically artefact kinds have artefacts as instances, I will argue that natural things can become 'adopted' into artefact kinds (Section 4). Widening the scope to include biological artefacts will show that self- 
reproduction is a further source of non-artificial instances of artefact kinds, and that there are artificial instances of natural kinds (Section 5).

\section{What Is an Artefact?}

One of the problems of giving a definition of "artefact" is that it is neither common currency nor unambiguous. In English, it also carries the meaning of an unintended side effect of a theory or technology. But hammers and screwdrivers, pet examples of artefacts in the sense to be defined, are no unintended side effects but tools very much intended by their producers and often searched after by their users. While often misleading, etymology can lend a helping hand here. The word "artefact" derives from the Latin noun ars and the Latin verb facere, the equivalent of the English verb "to make". Ars, in turn, is the Latin equivalent of the Greek noun technê, meaning "craft" or "skill", which is often used as in opposition to "nature", physis. An artefact, then, is something made by help of a craft or skill in opposition to those things grown naturally. ${ }^{1}$

As a first attempt, "artefacts" are often rendered as "man-made objects" (Dipert 1993:14), as "man-made as opposed to natural" (Simon 1969:6) or as "products of human actions" (Hilpinen 2008). Hammers, power plants and atomic bombs clearly are man-made, and so are money, companies, NGOs, and political borders. But due to the "man" component, this characterization is unduly anthropocentric (Simons \& Dement 1996:258) and in modern ears even chauvinistic, as "manmade" obviously has to include things made by women (Simon 1969:2 n. 1). It would exclude anything made by members of species other than Homo sapiens. But it shouldn't be a matter of definition that no artefacts are ever produced by extraterrestrial intelligent beings. And it is also worth a thought whether animals should - by trivial definition - be unable to produce artefacts, and whether the nests of birds or the dams of beavers should be disregarded as artefacts just because they are made by non-humans. ${ }^{2}$

\footnotetext{
${ }^{1}$ Simons \& Dement (1996:257) point out that the need of a skill comes in degrees, as some artefacts require more or higher skills than others. Nevertheless, we normally do not regard artificiality as a gradual affair.

${ }^{2}$ As Franssen (2009:21) puts it: "The lilies of the field may not toil or spin, but many animals do [...]." Hilpinen (2008) contemplates on (but is himself not decisive about) the possibility of non-humans as authors of artefacts. For an overview on "animal artefacts", cf. Gould (2007).
} 
In any case we are in want of a more refined account of what it is to be an artefact. Such an account has been suggested by Randall Dipert, the author of one of the few philosophical monographs on artefacts. Dipert construes tools as a subtype of instruments, and "the class of tools can be divided into the class of artifacts and the class of nonartifactual tools" (Dipert 1993:27-28). While he uses the term "instrument" for "an object that has been intentionally used in intentional activity", he reserves the term "tools" for "intentionally modified instruments". He then goes on to define "artefact" as "an intentionally modified tool whose modified properties were intended by the agent to be recognized by an agent at a later time as having been intentionally altered for that, or some other use" (Dipert 1993:24, 28 and 30-31). We thus get the result that an artefact is

(1) an object that has been intentionally used in intentional activity, which

(2) has been intentionally modified

(3) such that its modified properties were intended by the agent to be recognized by an agent at a later time as having been intentionally altered for that, or some other use.

Let us discuss these three Dipertian requirements in inverse order. Clause (3) does not exclude things that are being made for immediate use. But it excludes things from being artefacts where this immediate use comes along with its destruction. Certain chemical products or the products of induced atomic decay may be so short-lived that they cannot be stored for later use, but need to be used immediately. These things could at most be Dipertian tools, but not Dipertian artefacts. While being made for later use is a feature of many everyday artefacts like screw drivers and power plants, it does not seem to fit all cases. We will therefore not insist on this clause, lest we use "Dipertian tool" and "Dipertian artefact" as technical terms.

According to clause (2), a thing has to be modified in order to be an artefact or a Dipertian tool in general. Literally, clause (2) requires that the artefact itself must be the object of some intentional modification. This implies that there can be no unmodified artefacts, which is an unwelcome implication, because artefacts may well be left untouched after 
their production. ${ }^{1}$ It is more reasonable that something else has been modified in order to create the artefact: The creation of $x$ is never a modification of $x$, because $x$ is not yet there to be modified. The creation of an artefact may be the modification of its matter, as in the case of pottery, where some ceramic material is modified by heat. Or it might be, as in the case of the production of a car, the proper arrangement of its various pre-existing assembly parts.

One could try to resolve this difficulty by identifying the artefact with its material substrate: A wooden table, then, is just some wood in a certain arrangement, and a fork just some metal modified in such a way that we can pick food with it. This approach, however, has severe limitations, not least because some artefacts are non-material entities and thus do not have any material substrate with which they could be identified (Section $3)$. No matter how we decide on this issue, we can provide for this problem by replacing (2) with $(2 *)$, claiming that an artefact is:

$\left(2^{*}\right)$ an entity that came into existence through an intentional activity aimed at producing this very object.

According to clause (1), nothing can be an artefact before it is intentionally used (i.e., it has to be an instrument in Dipert's terminology). Thus, according to this definition, there cannot be any unused artefacts, for the mere production of a thing is not yet a use of it. Dipert solves this problem as follows:

Observe that all tools are contemplated instruments, since at least one efficacious property, namely, the modified one, has been thought to be a means to an end; a tool is a full-fledged instrument if it has been intentionally used for the contemplated purpose. (Dipert 1993:28)

We thus have to modify the definition and replace (1) with $\left(1^{*}\right)$, and say that an artefact is:

$\left(1^{*}\right)$ an object that has been intentionally used in intentional activity or that has been contemplated to be used in such a way.

\footnotetext{
${ }^{1}$ Taken at face value, this clause also excludes, contrary to Dipert's intentions (cf. Dipert 1993: 11 and Ch. 11), events from being artefacts, as events cannot be changed or modified (Dretske 1967). Dipert (1993:14) himself acknowledges that it is "a bit odd" to refer to an event as an artefact, thus in this paper I will restrict my discussion to continuants (i.e. perduring entities without temporal parts).
} 
A common feature of clauses (1), (1*) and (3) is that they all refer to the use made of the artefact, and clause (3) implies that we can distinguish different ways to use an artefact, one of which is the use intended by the producer. The producer, that is, can be described as having two nested plans, a product plan and an action plan, such that the product plan lays out the production of an entity that can then be used to realize the action plan (Houkes et al. 2002). While the use plan tells us which use the producer intends for the artefact, the production plan tells us how he intends to produce it. The intended use is often called the function of an artefact. Broadly conceived, even works of art can be ascribed functions, namely the function to be perceived and valued by connoisseurs and critics. The ascription of such a function does not imply that this function is ever realized. The backup system in a nuclear power plant may have the function to cool down the fuel assembly, even if it is never brought to exercise this function. We can thus rephrase clause (1) one more time:

$\left(1^{* *}\right)$ an object that has been ascribed a function by its producer.

We end up with the following modified definition:

An artefact is an object that came into existence through an intentional activity that aimed at producing this very object in order to fulfil a function ascribed to it by its producer.

Intentionality thus plays a double role in the characterization of artefacts: First, artefacts are things that can intentionally be used to fulfil a certain function, and second, artefacts are themselves intentionally produced in order to fulfil their function. ${ }^{1}$ Being a hammer thus is in a very specific way mind-dependent. To be a hammer means to have been created in order to serve as a hammer, to have been imposed, that is, the function of a hammer. This function, first, determines the essence of the artefact: it tells us, what a hammer is, by telling us what it is for. Artefact kinds,

\footnotetext{
${ }^{1}$ This is a recurring claim about artefacts. Cf. already Weber (1921: § 1/I): “[ [...] every artifact, such as for example a 'machine', can be understood only in terms of the meaning which its production and use have had or will have for human action; a meaning which may derive from a relation to exceedingly various purposes. Without reference to this meaning such an object remains wholly non-understandable." Cf. also Searle (1995: 10); Hennig (2007:90); Stemmer (2008:2). For a discussion of the understanding of artefacts, cf. Dipert (1993: Chs. 4-5) and Scholz (2002).
} 
therefore, are functional kinds; all instances of an artefact kind are intended to serve the same function. Second, hammers are produced to fulfil this function; hence the function tells us, why hammers exist. Third, hammers can be good or bad, and they can not only be used but also abused, and these predicates are, again, evaluated with respect to the hammer's proper function: A good hammer needs to have other qualities than a good shirt.

\section{Money Is Not a Money-Like Arrangement of Material Parts}

It is often said that a simple way to bring about artefacts is to take preexisting material things and assemble them in a new way. Put stones together in an appropriate way, and you get a wall. Take an appropriate piece of metal and affix a lengthy piece of wood, and you get a hammer. This observation is sometimes accompanied by the claim that mere rearrangement of pre-existing things does not bring about a new thing:

Artisans do not create; not, at least, in the sense of causing things to exist. They rearrange objects in space and cause bonding relations to begin to hold or to cease to hold [...]. But, in the last analysis, the labours of Michelangelo and the most skilled watchmaker are as devoid of true metaphysical issue [...]. All these people are simply shoving the stuff of the world about. (van Inwagen 1990:127)

If this was true, there would be no hammers. But we probably do not want to deny that everyday statements about hammers (like "There are three hammers in the workshop") are meaningful and often true. We need, therefore, some linguistic replacement for whatever appears to us as true propositions about hammers, and we could borrow the ersatz principle that Peter van Inwagen suggests for inanimate material complexes. According to this principle, there are no hammers, but there are material particles that are arranged in a hammer-like way and are subject to hammer-maintenance-stories (cf. van Inwagen 1990:133). We may try to generalize this approach as follows:

For any purported entity of a non-basic kind $F$ the following holds: There is no $F$, but there are material particles that are arranged $F$-wise (and are at present subject to a history of $F$-maintenance).

This general principle indicates how van Inwagen could translate a sentence of everyday language like "There are three hammers in the work- 
shop" into a sentence of an ontologically correct "language of refuge" (van Inwagen 1990:131). Here is my suggestion:

Within that complex of molecules that are ordered workshopwise and are subject of a workshop-maintenance-story are three spatially disconnected complexes of molecules that are ordered hammerwise and currently subject of hammer-maintenance-stories.

Our simple everyday sentence turns out to have a very complex counterpart in such ontologically correct language. This shows that everyday language has clear communicative advantages, but in itself that is no crucial argument against this kind of eliminativism. To criticise this position I will now draw the reader's attention to the case of money, whose ontology has been discussed, among others, by Ingvar Johansson (Johansson 2004:292-297 and Johansson 2005). I will show that the general principle sketched above fails for money on several counts.

According to our definition, money clearly is an artefact: It has intentionally been made and it is intended to fulfil a certain function, i.e. to serve as a means of exchange. Coins and bank notes would even satisfy Dipert's third criterion: They are meant to be recognizable. But the ersatz principle fails to account for money. In the first place it fails because being arranged in the proper way is not sufficient for being, say, a bank note. For a real banknote and a counterfeit banknote may consist of molecules that are arranged in exactly the same way, and still one of them will be legal tender and the other one will not. The difference between a banknote and counterfeit money is not so much due to their physical structure as to their origin and their legal status. A replica of a banknote, sharing all physical properties with the banknote, is nevertheless counterfeit money because it has not the status of being a banknote transferred on it by the legal authority. Being composed of atoms of the very same type that are arranged in the very same manner is thus not sufficient for being a banknote, even if they were involved in the same exchange practices. ${ }^{1}$

\footnotetext{
${ }^{1}$ From this perspective, I do not understand why Strub (2002:223) thinks that a counterfeiter must use an entity, that shares some, but not all "natural properties" with the original. This might be the case for someone who wants to pass on some yellow stuff for gold. But as far as banknotes are concerned, counterfeit money is no money although both may share all physical properties.
} 
The example of money also indicates that some of our everyday things can be quite flexible with regard to their physical structure, as John Searle observes:

Money can be bits of metal, slips of paper, wampum [i.e., shell beads; L. J.], or entries in books. In fact, most of our money in the past couple of decades underwent a revolutionary physical transformation that we did not even notice. Most money is now in the form of magnetic traces on computer disks. (Searle 1995:34)

So, a further problem for the ersatzist of the van Inwagen type is clear: What exactly is a money-wise arrangement, if not only pieces of paper and bits of metal, but also shells and bones can be used as money? Thus there is no specific money-wise arrangement of particles having which is necessary to be money.

Searle rightly remarks that only a tiny fraction of today's money exists in form of coins and bank notes. By now, most money is electronic money or book money. It has been observed before that not everything "man-made" is material: "Rules, instructions, and organizational schemes, for either men or machines, are not", Maarten Franssen, for example, remarks, and, he continues, "they form a special, elusive category that merits more philosophical attention" (Franssen 2009: 21). Electronic money belongs to this elusive category.

It is obvious that money is not a natural thing but an artefact. Natural things like conch shells and large stones may be bearers of the status function of being money, but this status function is an institutional matter. Searle has suggested that we analyse the construction of the social world as the imposition of an institutional status onto a bearer entity by means of constitutive rules of the form " $\mathrm{X}$ counts as $\mathrm{Y}$ in context C" (Searle 1995): A piece of paper can count as a 10 Euro note in the context of the European currency system. But there is not always a natural entity at the "bottom" of a social entity. As Barry Smith pointed out, there are "free-standing Y terms": there are no natural entities that have the status "obligation" or "company" or "book money" (Smith 2003a, 2003b). ${ }^{1}$ Such entities are "quasi-abstract" (Smith 2008): They

\footnotetext{
${ }^{1}$ Searle (2010) is happy to acknowledge this and other problematic phenomena and tries to incorporate them in his wider theory.
} 
may have a temporal beginning and a history, but they have no place. They have a temporal but not a spatial location. ${ }^{1}$

We thus have two types of social entities. The first is the case of a material $\mathrm{X}$ getting status $\mathrm{Y}$. In the second case, there is no material bearer for the social status, no $\mathrm{X}$ counting as $\mathrm{Y}$. Thus on the one hand we have things like banknotes; on the other hand we have things like book money or corporations. Though banknotes are not mere arrangements of material particles, they are materially constituted: They exist because certain rights and obligations are connected with a certain material bearer that, together with these rights and obligations, constitutes them (Jansen 2009). Book money and corporations are not materially constituted, like the rights and obligations that are connected with them. Rights and obligations themselves are neither material nor physical entities, but, again, quasi-abstract entities having a history, but no spatial location. Nor do rights and obligations depend on their being remembered: My obligations do not cease to exist only because I happen to forget about them. Thus quasi-abstract entities like obligations need neither documentation nor memories to persist. Nevertheless, quasiabstract entities are still connected to the physical realm, because they come about by commissive or declarative speech acts, i.e., promises or declarations, and speech acts are again bound to physical events like sound waves or the drawing of certain lines on paper. In order to bring about quasi-abstract artefacts we thus have to - intentionally - produce the respective establishing speech acts and by this means we bring about the quasi-abstract entity in question: We promise in order to bring about an obligation, we sign a contract to transfer property, and we register in order to found a corporation.

In the case of oral speech acts, there will normally be no persisting traces. In the case of written speech acts, however, documents are generated which often remain in existence long after the establishing speech act is over. Depending on the legal system, written documents might be necessary for certain purposes, e.g., to found a corporation. We have, however, seen that some quasi-abstract entities can exist without documents. Nevertheless, some philosophers assume that quasi-abstract entities like book money or corporations are constituted by such docu-

\footnotetext{
${ }^{1}$ Contrast this with a hammer: It has also its non-material aspect, being historically dependent on its maker's intention, but it has a clear spatial location.
} 
ments (Ferraris 2007, Smith 2008, Searle 2010). But this cannot be true: There are, no doubt, printed numbers on my monthly bank statement and physical traces on the bank's hard discs, and there are physical traces in the business register. However, these physical traits do not themselves count as money or as the company: I cannot buy anything in exchange for my bank statement or for the traces on the bank's hard disc. These physical traces rather count as signs for the money or the company. Though these signs may be tightly bound to the entities designated by laws or customs, they are normally not necessary for the existence of the social artefacts they represent. ${ }^{1}$

We thus end up with three grades of physical involvement. When they are the object of the proper we-intentions, physically manifest things

- can be the bearer of a social status and thus materially constitute social things, or

- they can represent social things, or

- they can be the material substrates of the establishments of social things.

In these cases, the physical entity counts either (1) as having the status in question, (2) as being a sign for other social entities, or (3) as acts of establishment of social entities. And thus we have to distinguish three different relations that can obtain between physically manifest things and social things

The social world is not uniform, and thus there is no single way to construct all social artefacts. A central role, however, can be ascribed to Searle's counts-as schema as a means either to confer a status on a material object or to describe the status of an object. In the simple case, we have a single plural subject that confers a status on a single material thing. In more complicated cases, there is no material object that can be identified as the material bearer of a status. Examples for this are book money and deontic entities like obligations, but also companies and other organisations. What is, however, indispensible, is the collective agent as the subject of a status ascription and her intentions. Thus the case of social artefacts makes it clear that artefacts are only accidentally material, but they are of necessity intended things.

\footnotetext{
${ }^{1}$ There may be exceptions to this rule due to special legal requirements.
} 


\section{Non-Artificial Instances of Artefact Kinds (1): Adoption}

Even everyday tools like hammers turn out to be problematic for the ersatzist strategy discussed. When you are camping and want to put up your tent, a stone may come in handy in order to hammer down the tent pegs. Such a stone can indeed be regarded as a very compressed and solid arrangement of molecules, and this is sufficient to tap in the tent pegs. This is a simple story: Some natural thing is found and used for a certain purpose. It is a Dipertian instrument. But most tools that surround us (like hammers) and for which we have special names (like "hammer"), have a complex history: Normally, hammers are produced by hammer makers in order to be put to service by hammer users for special purposes. Let us imagine that, in the course of a rare and strange cosmic incident, a bunch of molecules arranges itself in a hammer-wise way. This 'swamp hammer' will be a complex of particles arranged in a hammer-wise way. Picking up on the discussion of function in Section 2, we can conclude that this 'swamp hammer' differs from a hammer in various respects: First, the hammer function has never been imposed on this object: It has neither been produced with the intention to serve as a hammer nor has it ever been used as such. While a proper hammer comes into being in order to serve certain purposes, this is not true for the spontaneously arranged molecules of the 'swamp hammer'. Second, of hammers we can say, with regard to their proper functions, whether they are good or bad hammers. Such a non-aesthetic ${ }^{1}$ evaluative vocabulary is, however, not appropriate for mere arrangements of molecules. Third, a hammer can be abused, e.g., to kill someone. No such thing, however, could be said about the merely hammerwise arranged molecules. The 'swamp hammer' could indeed be used for various things - as a hammer as well as a weapon, but it would be odd to say of such an objet trouvé that it is being abused: There is simply no standard for correct use of such a chance thing.

The focal feature in these three arguments is, of course, the function that a hammer serves. Like other artefacts, hammers are embedded in social networks of producers, buyers and users and their social practices. It is because of these networks and practices that hammers in particular

\footnotetext{
${ }^{1}$ This restriction is necessary, for aesthetic-evaluative adjectives like "beautiful" can also be truly applied to stones on a beach, to a sand dune, and, come to that, to molecules arranged hammerwise.
} 
and artefacts in general can be assigned proper functions. Mere hammerwise arranged particles have not been ascribed a function. Thus there are neither good nor bad aggregates of particles; nor can mere aggregates of particles be evaluated or abused. Again, the functions of artefacts determine their essence, explain their coming-to-be and are the basis for their peculiar valuation standards (Section 2). In a word: Chance entities may be useful things, but they are not intended to be such, and as they have no ascribed function, they are also no artefacts according to our characterization in Section 2.

It is, of course, possible that a function will be ascribed to the aggregate of particles by its finder. The finder may erroneously believe that the object was created in order to fulfil this function, for its physical properties are not different from the physical properties of other hammers. The object's history, however, reveals that it differs from hammers in two important respects: First, its coming-into-being was not an act of hammer-production, as is normal for a hammer. Second, it differs from a hammer with respect to what Dipert has called its "deliberation history": Nobody has yet thought of it as a hammer. ${ }^{1}$ This is, of course, subject to change. By assumption, the chance entity may share all intrinsic physical properties with man-made hammers, and thus nothing hinders the finder to regard it as a hammer, to use it as a hammer, or even to sell it as a hammer. When this happens, the hammer function and the respective hammer status are being transferred to the chance entity, and thus the chance entity gets "adopted" as a hammer by its finder. It now becomes the object of hammer-intentions, and we can say that it then has become a hammer by being the object of appropriate hammer-intentions. Although it lacks the canonical origin of a hammer, it can fulfil the hammer function as well as hammers that are intentional products of hammer makers. By way of adoption, the chance entity has now become a hammer; it is now an instance of an artefact kind. It would be strange, however, to say that the chance entity has thus become an artefact, for even if it gets 'adopted', it had not to be altered, let alone skilfully altered in any way. Thus it is possible that a hammer is a Dipertian instrument only. Adopted hammers are instances of artefact kinds that are not artefacts, as they lack the artificial origin.

\footnotetext{
${ }^{1}$ Dipert (1993). Cf. his index under "deliberative: history of an object".
} 
Note that money behaves different in this respect: Should paper fibres assemble by chance to form a piece of paper that resembles a banknote, then this wouldn't be money even if people started to use it as such. Such an aggregate is no more a banknote than man-made counterfeit money is. It happens again and again that counterfeit money is taken for real and becomes the object of money-intentions. Nevertheless, it remains counterfeit money. Counterfeit money does not become money by being adopted into the relevant social practices, though it is conceivable that nobody ever realizes that it is, in fact, counterfeit money. The same applies to 'swamp money'. In the case of banknotes, the canonical origin is essential: The status of being a banknote has to be transferred explicitly (and, in legal terms, correctly) by the respective bank of issue. It is thus not sufficient to be useful for a certain purpose to be a banknote: Banknotes must have been intentionally produced to fulfil this function. Every banknote is thus of necessity an artefact. We could thus call banknotes an exclusive artefact kind, every instance of which is an artefact. Members of an exclusive artefact kind, that is, must of necessity have an artificial origin. Hammers, on the other hand, are not in this sense exclusive: We can continue to call hammers an artefact kind, because hammers normally are artefacts. But as our thought-experiment shows, there could well be hammers that do not have an artificial origin but came into existence as a chance entity and are only later adopted as hammers. Hammers thus form a non-exclusive artefact kind that allows for members without an artificial origin.

\section{Non-Artificial Instances of Artefact Kinds (2): Self-Reproduction}

The case of electronic money clearly shows that not all artefacts come into being by intentional re-arrangement of pre-existing material parts. Not even all material artefacts can be created in this way: Metals have to be fused to yield a new alloy. New chemical compounds have to be synthesised. These processes are only inadequately described as a spatial re-arrangement of pre-existing atoms or molecules, and obviously artisans knew how to make bronze tools long before scientists knew anything about subatomic particles. While the melting process is intentionally induced, the combination process is, in a way, a natural one: It happens without further human intervention. Still we would say that bronze is a man-made alloy in the strong sense: It is used for certain purposes and intentionally produced to serve these purposes. While 
chemical elements are otherwise prototypical candidates for natural kinds, some elements do only exist when being intentionally produced with highly complex technologies, and they may be useful for some purposes. The transuranic element Americium, for example, is comercially used in smoke detectors, and Glenn Seaborg, who invented the technology to produce it, was granted a US patent not only for the production technology, but also for the element itself. ${ }^{1}$

Similar things occur in the biological realm. Ages ago, humans domesticated animals, and they intentionally crossbred animals and plants to gain new varieties better adapted to human needs (Sperber 2007). In these cases, not only the particular animals, but also the variety itself can be considered as an artefact. Thus, as Herbert A. Simon warns us, we have to "be careful about equating 'biological' with 'natural'. A forest may be a phenomenon of nature; a farm certainly is not." (Simon 1969: 5). Technological potential has multiplied with genetic engineering, i.e. the direct manipulation of the DNA, followed by a growing process that is not in itself controlled by the genetic engineer. In this way, new genetic strains and wholly new species can be engineered, involving several of such pairs of intentional manipulations as triggers and natural processes triggered by it. This way, we not only produce particular biological artefacts, but also new biological kinds, i.e. artefact kinds whose members are biological entities. Researchers and industry do also apply for patents on arteficial biological kinds, both for plants and for animals. One of the more prominent examples is the OncoMouse, which has been developed in Harvard and marketed by DuPont as a laboratory animal especially useful for cancer research (Murray 2010).

Biological entities, and biological artefacts, range from amino acids via proteins to cells and living beings. As living beings, biological artefacts may have the ability to procreate, and this may lead to offspring of the same kind without further human intervention. With non-living artefacts, every instance of an artefact kind has to be produced through intentional action; hence any instance of these artefact kinds belongs, so to speak, to the 'first generation'. If biological artefacts can procreate, this leads to the possibility of instances belonging to succeeding generations. The members of, say, the second generation may come into exist-

\footnotetext{
${ }^{1}$ Patent US 3.156 .523 (1964-11-10) Glenn T. Seaborg, Element 95 and Method of Producing Said Element, http://www.pat2pdf.org/patents/pat3156523.pdf.
} 
ence without any further human intervention: These particular entities are no products of intentional actions, and thus no artefacts. Hence we will have instances of a (biological) artefact kind that are not artefacts.

In order to corroborate this point, I will first turn to the case where the outcome of an intentional human intervention is a new instance of a previously existing natural kind. Test tube babies are an example for this first variety. Human kind is not an artefact kind, but a natural kind. However, some instances of this kind may be regarded to be artefacts: Human in vitro babies are intentionally produced entities, they have an artificial origin. Test tube babies come intentionally into existence through the intentional application of biotechnological knowledge, and thus there is a good reason to conceive of them as artefacts. ${ }^{1}$ But though the intentional application of biotechnological knowledge is sometimes helpful, the application of such technical knowledge is, obviously, not necessary for a baby to be conceived and born. Homo sapiens is a selfreproducing kind, and there is no need to have intentions in order to beget children. Moreover, there is no difference in kind between the children whose parents intended to procreate and those who did not (Grandy 2007:24), and neither is there a difference in kind between human babies conceived in vivo and those conceived in vitro. Hence we have artificial instances of a natural kind.

In other cases, human intervention may produce not only new instances of a pre-existing kind, but a totally new kind may be created. Examples for this are mules, Persian cats and transgenic maize. They all have been bred specifically in order to fulfil certain functions. Mules are the offspring of a male donkey and a female horse - an equine hybrid variety that is valued for a combination of positive qualities. Donkeys and horses normally do to not mate without the intervention of human breeders. Thus mules came about through human intervention. Mules can thus be regarded as an artefact kind. As nearly all mules are infertile, mules are normally not self-reproducing. Hence virtually no mule comes into existence without human intervention at all. Hence virtually all

\footnotetext{
${ }^{1}$ Normally we refrain from ascribing functions to human beings. But in any case test tube babies fit the pattern of a nested 'production plan' and 'use plan': Infertile parents may imagine to live together with their child-to-be (the use plan) and then look for reproduction-technological means to beget a child (the production plan). If still in doubt, the reader may just choose another species.
} 
instances of the kind mule have an artificial origin; they are intentionally produced entities.

Today, biotechnology companies create new biotechnological kinds at a very high pace. This development had reached a peak, when in 2010 the J. Craig Venter Institute reported "the design, synthesis and assembly" of a bacterium whose entire genome was synthesised and then transplanted into a recipient cell (Gibson 2010:1). New biological kinds abound in these days as the products of synthetic biology, and these kinds obviously come into existence through their first instances.

But what about instances of such an artefact kind that are not the first ones of their kind? This depends, at least in part, on whether its instances can procreate or not. Normally, mules cannot procreate, whereas Persian cats and transgenic maize can procreate. If the members cannot procreate, i.e., if they cannot reproduce their kind, each instance of this kind must be produced anew with biotechnological means (old or new). As a rule, all instances of artefact kinds that are not self-reproducing are artefacts. Up to now, self-reproduction is restricted to living beings. Hence this rule concerns all non-living artefacts, the exception of the rule being adoption cases. ${ }^{1}$ Using the terminology introduced in Section 4 , we can describe these as forming exclusive artefact kinds. If, however, instances of an artefact kind can procreate, then it is a self-reproducing kind and no intentional human intervention is necessary to bring about further instances. Hence an artefact kind can have instances which are not artefacts. A 'second generation' plant of transgenic maize, for example, need not be an artefact according to our characterization in Section 2, as it might come into existence without any further intentional intervention. Were we to claim artefact status also for these second generation plants for the reason that they are offspring of an artefact, we would have to ascribe artefact status also to the children of people that have been

\footnotetext{
${ }^{1}$ It is conceivable that robots can be programmed to build further instances of their own kind. In this case we would have a self-reproducing kind that is not a biological kind. Would robots of succeeding generations be artefacts? Maybe not, because they come about without further intentional intervention: In this case, not everything technological would be an artefact in the sense defined. But the use plan for the first robot may have explicitly assigned to it the function to produce further robots. In this case it could be seen as a means of production of the second generation robots, which then could be counted as artefacts.
} 
conceived in vitro. A second generation plant is presumably as useful as a 'first generation' plant, but it can come into being without any intentional intervention on the side of the farmer. Self-reproducing artefact kinds are, thus, of necessity non-exclusive artefact kinds.

Table 1: Four varieties of artificiality in biological kinds

\begin{tabular}{|c|c|c|}
\hline & Engineered: Artificial essence & Evolved: Natural essence \\
\hline \multirow[t]{2}{*}{$\begin{array}{l}\text { Self- } \\
\text { reproducing }\end{array}$} & $\begin{array}{l}\text { First instances need to be } \\
\text { artefacts, but later instances } \\
\text { need not be artefacts. }\end{array}$ & $\begin{array}{l}\text { Natural kind, but instances may in } \\
\text { special circumstances be artefacts. }\end{array}$ \\
\hline & Example: transgenic maize. & Example: in vitro babies \\
\hline \multirow[t]{2}{*}{$\begin{array}{l}\text { Not self- } \\
\text { reproducing }\end{array}$} & $\begin{array}{l}\text { Artefact kind: Instances } \\
\text { normally are artefacts. }\end{array}$ & $\begin{array}{l}\text { Natural kind, but instances may in } \\
\text { special circumstances be artefacts. }\end{array}$ \\
\hline & Example: mules, hammers. & Example: nature-identical flavours. \\
\hline
\end{tabular}

An overview of these different types of biological artefacts is presented in Table 1. On the one hand, thus, there are artefacts that are artefacts because they have an engineered essence, like hammers and mules, as these entities normally are artefacts. On the other hand, there are artefacts, like in vitro babies or nature-identical flavours, which are artefacts although they have no engineered essence and belong to a natural kind. We have seen in Section 3 that some artefact kinds, like the kind hammer, allow for instances of non-artificial origin by way of adoption. Also the kind mule can have the odd non-artificial instance, because there is no metaphysical hindrance that donkey and horse mate without human intervention, and probably we would not wait for an act of adoption to call it by the name mule. In the case of self-reproducing artefact kinds the number of instances with a non-artificial origin may by far outnumber the instances of artificial origin. All this shows that there are also things that are not artefacts, although they belong to an artefact kind.

This has important implications for our concept of artefacts. For then not all artefacts belong to an artefact kind, because some of them belong to natural kinds, while some instances of artefact kinds might well not be artefacts: A test tube baby has an artificial origin, but is a normal member of the kind Homo sapiens. In the end, human in vitro fertilization is, as such, only a special way to generate humans, and not a way to generate entities of some other kind. We thus can have members of a natural 
kind with an artificial origin or with artificial properties or both. What makes these things artefacts is that someone intentionally interfered with the things or with the stuff from which they developed or which had a causal role in their development, be they cells like the egg cell or the sperm, or molecules, like the DNA.

\section{Conclusions}

In this paper, I have discussed a wide variety of artefacts: non-living material artefacts like hammers, living artefacts like transgenic maize and test tube babies, and social artefacts like money. We have seen that it takes both more and less than a re-arrangement of pre-existing parts in order to produce artefacts: It takes more, because artefacts must be intended things, and thus an artefact is historically mind-dependent. It is not possible that an artefact comes into existence without an intention to this effect. If we know that artefacts exist at a certain time, we know that there must have been an intention at a preceding time.

But in some cases it takes also less than a re-arrangement, for an artefact is not necessarily an inanimate material thing. Some artefacts, like electronic money, are even immaterial, with no material parts at all. We have also seen that some artefacts are living beings with the ability to procreate. The fact that some artefact plants or animals can procreate brings it about that not every entity with an engineered essence needs to be an artefact. On the other hand, some instances of natural kinds may well be artefacts, as is shown by human test tube babies that are fullfledged members of our species. The argument, in a nutshell, is that artefact kinds are functional kinds, whereas it is the historical origin that decides whether or not an individual is an artefact.

The upshot of this is that we deal with two independent distinctions here. Belonging to an artefact kind and being an artefact are two independent features: The first distinction divides off artefacts from nonartefacts; the second distinguishes between instances of artefact kinds and instances of natural kinds. These two distinctions are orthogonal to each other, and besides the two canonical combinations of artificial instances of artefact kinds and non-artificial instances of natural kinds there are also non-artificial instances of artefact kinds and artificial instances of natural kinds. Any ontology that aims at an adequate de- 
scription of the biological as well as the social world has to take this into account. $^{1}$

\section{References}

Dipert, R. R. (1993). Artifacts, Art Works, and Agency, Philadelphia: Temple University Press.

Dretske, F. (1967). “Can Events Move?”, Mind, 76:479-492.

Ferraris, M. (2007). "Documentality or Why Nothing Social Exists Beyond the Text", in Ch. Kanzian \& E. Runggaldier (eds.), Cultures. Conflict - Analysis - Dialogue, Proceedings of the 29th International Ludwig Wittgenstein-Symposium in Kirchberg/Austria, Frankfurt M.: Ontos, 385-401.

Franssen, M. (2009). "Design, Use, and the Physical and Intentional Aspects of Technical Artifacts", in P. Vermaas, P. Kroes, A. Light \& St. A. Moore (eds.), Philosophy and Design. From Engineering to Architecture, Dordrecht: Springer, 21-35.

Gibson, D. G. et al. (2010). "Creation of a Bacterial Cell Controlled by a Chemically Synthesized Genome", Science. doi: 10.1126/science. 1190719.

Gould, J. L. (2007). "Animal Artefacts", in E. Margolis \& St. Laurence (eds.), Creations of the Mind. Theories of Artifacts and their Representation, Oxford: Oxford University Press, 249-266.

Hennig, B. (2007). "Der Fortbestand von Lebewesen. Aus Anlass von Marianne Scharks Lebewesen versus Dinge”, Allgemeine Zeitschrift für Philosophie, 32:81-91.

Hilpinen, R. (2008). "Artifact", in E. N. Zalta (ed.), The Stanford Encyclopedia of Philosoph, Fall 2008 Edition, http://plato.stanford. edu/archives/fall2008/entries/artifact/

Houkes, W., \& Vermaas, P. E. (2009). "Contemporary Engineering and the Metaphysics of Artefacts: Beyond the Artisan Model", The Monist, 92:403-419.

\footnotetext{
${ }^{1}$ Many thanks to Ewa Binczyk, Peter Kroes, Johannes Röhl, Pieter Vermaas and an anonymous colleague for very helpful comments on earlier versions of this paper.
} 
Houkes, W., Vermaas, P. E., Dorst, K., \& de Vries, M. J. (2002). "Design and use as plans: an action-theoretical account", Design Studies, 23:303-320.

Jansen, L. (2009). "The Unity of Social Entities", in L. Honnefelder, E. Runggaldier (eds.), Unity and Time in Metaphysics, Berlin/New York: de Gruyter, 15-45.

Johansson, I. (2004). Ontological Investigations. An Inquiry into the Categories of Nature, Man and Society, $2^{\text {nd }}$ enlarged ed., Frankfurt: ontos verlag ( $1^{\text {st }}$ ed., London: Routledge, 1989).

Johansson, I. (2005). "Money and Fictions", in Kapten Mnemos Kolumbarium, Festschrift to Helge Malmgren,

http://www.phil.gu.se/posters/festskrift2/mnemo_johansson.pdf.

Murray, F. (2010). "The Oncomouse That Roared: Hybrid Exchange Strategies as a Source of Distinction at the Boundary of Overlapping Institutions", American Journal of Sociology, 116:341-388.

Scholz, O. R. (2002). "Was heißt es, ein Artefakt zu verstehen?", in Mark Siebel (ed.), Kommunikatives Verstehen, Leipzig: Leipziger Universitätsverlag, 220-239.

Searle, J. R. (1995). The Construction of Social Reality, New York: Free Press.

Simon, H. A. (1969). The Sciences of the Artificial, $2^{\text {nd }}$ ed., Cambridge MA/London: MIT Press.

Simons, P., \& Dement, Ch. W. (1996). "Aspects of the Mereology of Artifacts", in R. Poli \& P. Simons (eds.), Formal Ontology, Dordrecht: Kluwer, 255-276.

Smith, B. (2003a). "John Searle: From Speech Acts to Social Reality", in B. Smith (ed.), John Searle, Contemporary Philosophy in Focus, Cambridge: Cambridge University Press, 1-33.

Smith, B. (2003b). "The Ontology of Social Reality", American Journal of Economics and Sociology, 62:285-299; repr. in D. Koepsell \& L. S. Moss (eds.), John Searle's Ideas about Social Reality. Extensions, Criticism and Reconstructions, Malden MA/Oxford: Blackwell 2003, 285-299.

Smith, B. (2008). "Searle and de Soto: The New Ontology of the Social World", in B. Smith, D. M. Mark \& I. Ehrlich (eds.), The Mystery of 
Capital and the Construction of Social Reality, Chicago/La Salle IL: Open Court, 35-51.

Sperber, D. (2007). "Seedless Grapes: Nature and Culture", in E. Margolis \& S. Laurence (eds.), Creations of the Mind. Theories of Artifacts and their Representation, Oxford: Oxford University Press, 124-137.

Stemmer, P. (2008). Normativität. Eine ontologische Untersuchung, Berlin/New York: de Gruyter.

Strub, Ch. (2002). "Zur Normativität konstitutiver Regeln", in U. Baltzer \& G. Schönrich (eds.), Institutionen und Regelfolgen, Paderborn: Mentis, 207-224.

van Inwagen, P. (1990). Material Beings, Ithaca NY: Cornell University Press.

Weber, M. (1921). Basic Concepts in Sociology, translated and with an introduction by Herbert Pierre Secher, $2^{\text {nd }}$ paperback ed., New York: The Citadel Press, 1963. 